\title{
Correlates of Non-Physiological Behavior in Patients with Chronic Low Back Pain
}

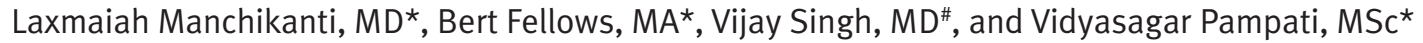

\begin{abstract}
It is widely believed that the extent of a patient's subjective complaints are often based on developmental, psychological, social, and cultural factors rather than structural or physical pathology. In patients presenting with chronic low back pain, underlying behavioral problems may not be immediately apparent. These behavioral or non-physiological issues may be secondary to a deliberate deception or may be associated with psychological distress. Waddell et al developed a standardized assessment of behavioral or non-organic signs and symptoms in hopes that such an evaluation of the patient could lead to better utilization of surgical and diagnostic procedures. Multiple
\end{abstract}

Among the many chronic pain problems, low back pain constitutes the majority of these problems, despite all the efforts expended into information, research, prevention, treatment and rehabilitation (1). Lifetime prevalence of low back pain has been reported as $65 \%$ to $80 \%(2,3)$. Cassidy et al (4) assessed the prevalence of low back pain and its impact on general health in the Canadian population. The results showed $47 \%$ of the patients reporting Grade I low back pain (low pain intensity and low disability), 12\% Grade II low back pain (high pain intensity and low disability), and 13\% Grade III and Grade IV (high pain intensity with moderate or severe disability) low back pain.

Chronic low back pain is a multifactorial disorder with many possible etiologies. It is recognized as a multidimensional problem with both sensory and affective components. The biopsychosocial model, which emerged in the 1980s,

From *Pain Management Center of Paducah, Paducah, Kentucky and \#Pain Diagnostics Associates, Niagara, Wisconsin. Address Correspondence: Laxmaiah Manchikanti, MD, 2831 Lone Oak Road, Paducah, Kentucky 42003. E-mail: drm@apex.net .

There was no external funding in preparation of this manuscript. authors have described varying results correlating excessive pain behavior with psychological disorders.

This study was designed to evaluate psychological correlates of pain behavior in 120 chronic low back pain patients in an interventional pain management setting with 60 men and 60 women. Patients were evaluated with completion of a physical examination, which included Waddell's non-physiological symptoms and signs, and psychological evaluation by Pain Patient Profile (P-3).

Results showed that 27 patients (22\%) presented with non-physiological symptoms,
34 patients $(28 \%)$ with non-physiological signs, and 19 patients (16\%) with combined presence of non-physiological signs and symptoms. Overall there was significant correlation of non-physiological signs with depression, anxiety, and somatization, both by diagnosis of depression, diagnosis of anxiety and elevated scores. However, correlation was present for non-physiological symptoms only with elevated scores of anxiety and somatization.

Keywords: Low back pain, pain behavior, non-physiological behavior, non-physiological signs, non-physiological symptoms, depression, anxiety, somatization views chronic spinal pain as a biopsychosocial phenomenon, in which biological, psychological and social factors dynamically interact with each other. Due to the ineffective diagnostic modalities in pinpointing the structural basis of low back pain, the concept of psychogenic pain has emerged. Psychogenic pain is considered in the context that "since there is nothing wrong with your body, there must be something wrong with you." The diagnosis of psychogenic pain not only fails to provide a valid organic diagnosis, but it also fails to provide validation of patients' symptomatology and complaints. Subsequently, the terminology of medically unexplained pain has been introduced. However, medically unexplained pain is not a symptom of a psychological disorder (5). Thus far, the proponents of medically unexplained pain have not provided empirical evidence to prove that psychopathology causes pain (5). Modern technology, including magnetic resonance imaging (MRI), computed tomographic axial scanning (CT), neurophysiologic testing and comprehensive physical examination with psychological evaluation, can identify the cause of low back pain in only $15 \%$ of the patients in the absence of disc herniation and neurological deficit (6-8). Overall, inaccurate or incomplete diagnosis in patients referred to pain treatment centers has been described as ranging from $40 \%$ to $67 \%$, and the incidence of psychogenic pain has been shown to be present only in 1 of 3,000 patients, with the presence of pain of organic origin mistakenly branded as psychosomatic in $98 \%$ of cases $(9,10)$. Staats et al (11) outlined the psychological behaviorism theory of pain with the description that pain phenomena and human behavior are complex.

It is widely believed that the extent of a patient's subjective complaints are often based on developmental, psychological, social and cultural factors rather than with structural or physical pathology (12). It is well known that in patients presenting with chronic low back pain, underlying behavioral problems may not be immediately apparent. These behavioral or non-physiological issues may be a deliberate deception, such as malingering (in order to obtain secondary gain) or factitious disorder (patient choosing to be in a sick role) or associated with psychological disorders. The association between depression and medically unexplained pain has been investigated extensively (13-17). Depression has been shown to be positively 
associated with somatization and somatoform disorders, in which medically unexplained pain may arise (13-17). Multiple hypotheses exist to explain the mechanisms by which psychological factors play a role in the etiology of otherwise unexplained pain $(13,17,18)$. However, contradicting opinions also exist $(5,11,19)$. Pain behaviors were initially described by Fordyce (20). He described verbal and non-verbal behaviors exhibited by pain sufferers, which he proposed served to communicate the fact that they are experiencing pain. In fact, in an interventional pain management setting, $29 \%$ of the patients presented with non-physiological symptoms and $23 \%$ with non-physiological signs, with $75 \%$ of the patients also presenting with at least one of the psychological conditions, including generalized anxiety disorder, somatization disorder, dysthymia, major depression or schizophrenia (21).

The importance of psychological evaluation and evaluation for non-physiological symptoms and signs has been stressed (21-25). These studies have shown that psychological disorders are much more common in patients presenting for management of chronic pain compared to the general population. Further, a number of studies also have indicated that depression is greater in patients with low back pain who display excessive pain behavior compared with those without such behavior (26-29). However, the magnitude of this difference between groups has been small. It also has been stated that the use of self-rated depression scales, validated for use in subjects with psychiatric illness has been shown to give exaggerated scores when used in subjects with physical complaints and is likely to have increased the magnitude of this association, making the results difficult to interpret $(30,31)$.

Waddell et al $(26,27)$ developed a standardized assessment of behavioral or non-organic signs and symptoms. Waddell et al (26), in 1980 proposed that eight signs could be grouped in five categories, assessed in standardized fashion, and utilized as an aide to the separation of structurally based pathology generated signs from those due to psychological processes. It was their hope that such an evaluation of the patient could lead to better utilization of inappropriate surgical and diagnostic procedures.

Despite the recognition that excessive pain behaviors are associated with psychological problems, the exact relation between the pain behaviors and psychological factors continues to be unclear. Dickens et al (17) tested the hypothesis that subjects exhibiting excessive pain behavior would be more depressed than those who did not exhibit excessive levels of pain behavior. Following the evaluation of 55 consecutive outpatients in the United Kingdom, they concluded that pain behaviors were not related to anxiety or depression in their group, even though gender differences between groups could have contributed to their negative findings. They opined that pain behaviors may influence other physical measures and further studies were required to investigate the relation between depression and pain behavior while controlling for gender differences. They concluded that the study indicated that care is needed in interpreting findings on any clinical measure of disease status because findings are likely to be affected by the subject's pain behavior.

This evaluation was undertaken to evaluate the correlation between common psychological conditions (anxiety, depression, and somatization) and excessive pain behavior in a consecutive series of patients with chronic low back pain.

\section{Methods}

The study was designed to evaluate psychological correlates of pain behavior in patients with chronic low back pain in an interventional pain management setting. The study population consisted of 120 consecutive patients presenting for evaluation and management of chronic low back pain with 60 men and 60 women patients. All patients presented for pain management. There were no specific inclusion or exclusion criteria. The patients were provided an explanation about their participation in the study and all patients participated with informed choice and consent.

Evaluation of the patients included completion of a standard comprehensive pain management questionnaire, history and physical examination by a physician, psychological evaluation by Pain Patient Profile (P-3), and evaluation of drug therapy and demographic features.

Demographic features of age, height, weight, type of referral, duration of pain in months, pain rating, and status of previous surgery were obtained from the patient history. The patient's age was calcu- lated from his or her birth date; whereas duration of pain was calculated based on the patient's memory of the onset of pain to the closest month, when available. Pain rating was obtained from a 10-point numerical pain-rating scale. The results of physical findings were based on examination of the patient.

Non-physiological signs were measured utilizing the checklist of non-organic signs devised by Waddell et al (26). The checklist of non-organic signs consisted of the items which included superficial or non-anatomic tenderness, complaints of pain on axial loading of the spine, or simulated rotation of the spine, limited straight-leg raising that is significantly increased on distraction, regional sensory loss or weakness that cannot be accounted by recognized pathophysiologic process, and overreaction to the clinical examination. A score of three or more positive non-physiological signs was considered as positive.

Non-physiological behavior was assessed using Waddell's checklist of nonorganic symptoms (27). Patients were asked whether they had ever experienced any symptoms from a list of five categories which included the descriptors of pain with lack of anatomic distribution (whole leg pain or tailbone pain), nondermatomal distribution, non-myotomal activity, lack of variance with time and activity and lack of variable benefit (intolerance to treatments and emergency admissions to hospital). A score of three or more positive non-organic symptoms were considered as positive.

Psychological evaluation was carried out by Pain Patient Profile or P-3. P3 is a test developed specifically for chronic pain patients with three clinical scales, which include depression, anxiety and somatization, along with a validity index that assesses the probability of random responding, inadequate reading comprehension, and magnification of symptoms. This test realizes that the average pain patient does have symptoms of depression, anxiety and somatization.

Data was recorded on a database using Microsoft ${ }^{\circledR}$ Access $^{\circledR}$ by a person not participating in the study. The SPSS version 9.0 statistical package was used to generate the frequency tables. Student's ttest was used to test mean significant differences between gender. Comparison of continuous variables was performed by using the Mann-Whitney $\mathrm{U}$ test. Cat- 
egorical data were compared using chisquared test. Fisher's exact test was used wherever expected value was less than 5 . Spearman correlation coefficients were calculated for measured variables. Results were considered statistically significant if the $P$-value was less than 0.05 .

\section{RESULTS}

\section{Demographic Features}

As shown in Table 1, there were no differences noted with age, type of referral, duration of pain or pain rating. However, a higher proportion of men underwent surgery. The height and weight of men were significantly greater than women.

\section{Psychological and Behavioral Characteristics}

As illustrated in Table 2, a significantly greater proportion of women presented with elevated scores and diagnosis of depression, elevated anxiety scores, a combination of depression and somatization, non-physiological signs and antidepressant therapy. However, diagnosis of anxiety, somatization, anti-anxiety therapy and non-physiological symptoms were similar in both groups.

Overall, 27 patients (22\%) presented with non-physiological symptoms, whereas 34 patients $(28 \%)$ presented with nonphysiological signs. Nineteen patients (16\%) presented with a combination of non-physiological symptoms and signs.

\section{Correlation of Non-Physiological Symptoms}

Non-physiological symptoms were correlated with psychological problems as illustrated in Table 3. Overall, patients with non-physiological symptoms had higher scores of anxiety and somatization. However, there was no significant difference noted between prevalence of diagnosis of depression, anxiety or somatization. On further analysis, among women, there were higher scores of depression, anxiety and somatization in patients with non-physiological symptoms. In contrast, there were no differences noted among the men. There were no differences noted in the diagnosis of either depression, anxiety, or somatization either among men or women.

No significant differences between men and women positive for non-physiological symptoms and depression, anxiety

Table 1. Demographic characteristics

\begin{tabular}{|c|c|c|c|}
\hline & Male & Female \\
\hline & & (6o) & (6o) \\
\hline \multicolumn{2}{|c|}{ Age (years) (Mean + SEM) } & $45 \pm 1.4$ & $43 \pm 1.7$ \\
\hline \multicolumn{2}{|c|}{ Height (Inches) (Mean + SEM) } & $70^{\star} \pm 0.4$ & $65 \pm 0.3$ \\
\hline \multicolumn{2}{|c|}{ Weight (pounds) (Mean + SEM) } & $201^{\star} \pm 5 \cdot 3$ & $171 \pm 6.1$ \\
\hline \multirow[t]{2}{*}{ Referral } & MD & $77 \%(46)$ & $73 \%(44)$ \\
\hline & Self & $23 \%(14)$ & $27 \%(16)$ \\
\hline \multicolumn{2}{|c|}{$\begin{array}{l}\text { Duration of pain (months) } \\
\text { (Mean + SEM) }\end{array}$} & $88 \pm 11.1$ & $101 \pm 14 \cdot 3$ \\
\hline \multirow{3}{*}{$\begin{array}{l}\text { Pain Rating } \\
\text { (Median) }\end{array}$} & Least & $5(3-6)$ & $5(4-6)$ \\
\hline & Worst & $10(9-10)$ & $10(9-10)$ \\
\hline & Average & $8(6-9)$ & $8(7-9)$ \\
\hline \multicolumn{2}{|c|}{ Previous Surgery } & $50 \% *(30)$ & $17 \%(10)$ \\
\hline
\end{tabular}

* Indicates significant difference

() Number of patients

Data are presented as median values (interquartile ranges: 25 th $-75^{\text {th }}$ percentile). Continuous variables are compared using the Mann-Whitney $\mathrm{U}$ test. Non-continuous variables are using the chi-squared test.

Table 2. Psychological and behavioral characteristics

\begin{tabular}{|l|l|c|c|c|}
\hline & & Male & Female & Combined \\
\hline \multirow{2}{*}{ Depression } & Score (Median) & $47(39-55)$ & $54^{\star}(45-60)$ & $51(42-58)$ \\
\cline { 2 - 5 } & Positive Diagnosis & $13 \%(8)$ & $3 \%^{\star}(18)$ & $22 \%(26)$ \\
\hline \multirow{2}{*}{ Anxiety } & Score (Median) & $47(39-56)$ & $51^{*}(44-60)$ & $50(51-56)$ \\
\cline { 2 - 5 } & Positive Diagnosis & $15 \%(9)$ & $22^{*}(13)$ & $18 \%(22)$ \\
\hline \multirow{2}{*}{ Somatization } & Score (Median) & $50(44-55)$ & $55^{\star}(48-60)$ & $51(46-56)$ \\
\cline { 2 - 5 } & Positive Diagnosis & $13 \%(8)$ & $22 \%(13)$ & $17 \%(21)$ \\
\hline Depression + Anxiety & $12 \%(7)$ & $17 \%(10)$ & $14 \%(17)$ \\
\hline Depression + Somatization & $7 \%(4)$ & $20 \%{ }^{*}(12)$ & $13 \%(16)$ \\
\hline Anxiety + Somatization & $8 \%(5)$ & $13 \%(8)$ & $11 \%(13)$ \\
\hline Non-Physiological Symptoms & $18 \%(11)$ & $27^{*}(16)$ & $22(27)$ \\
\hline Non-Physiological Signs & $17 \%(10)$ & $40 \%{ }^{*}(24)$ & $28 \%(34)$ \\
\hline $\begin{array}{l}\text { Combined non-physiological signs and } \\
\text { symptoms }\end{array}$ & $12 \%(7)$ & $20 \%(12)$ & $16 \%(19)$ \\
\hline Anti-depressant therapy & $33 \%(20)$ & $68 \% *(41)$ & $51 \%(61)$ \\
\hline Anti-anxiety therapy & $37 \%(22)$ & $53 \%(32)$ & $45 \%(54)$ \\
\hline
\end{tabular}

* Indicates significant difference

() Number of patients

Data are presented as median values (interquartile ranges: $25^{\text {th }}-75^{\text {th }}$ percentile). Continuous variables are compared using the Mann-Whitney $\mathrm{U}$ test. Non-continuous variables are using the chi-squared test.

and somatization were observed.

\section{Correlation of Non-Physiological Signs}

Overall, there was significant correlation of scores of depression, anxiety and somatization with non-physiological signs as illustrated in Table 4. The positive diagnosis of depression and anxiety were present, without the diagnosis of somatization. Among men, scores and diagnosis of anxiety and somatization were seen in a significantly greater proportion of patients with non-physiological signs. Among women, there were no significant differences noted with the diagnosis or scores of depression, anxiety and somatization.
Comparison of men and women showed no significant differences among the patients positive for non-physiological signs with regards to diagnosis or scores of depression, anxiety, and somatization

Correlation of Non-Physiological Signs and Symptoms

Sixteen percent of the patients presented with combined non-physiological signs and symptoms. When compared to the overall sample, there was significant correlation between the scores and diagnosis of non-physiological symptoms and signs with elevated scores and diagnosis of all three psychological variables, namely depression, anxiety and somatization. 
Table 3. Correlation of non-physiological symptoms

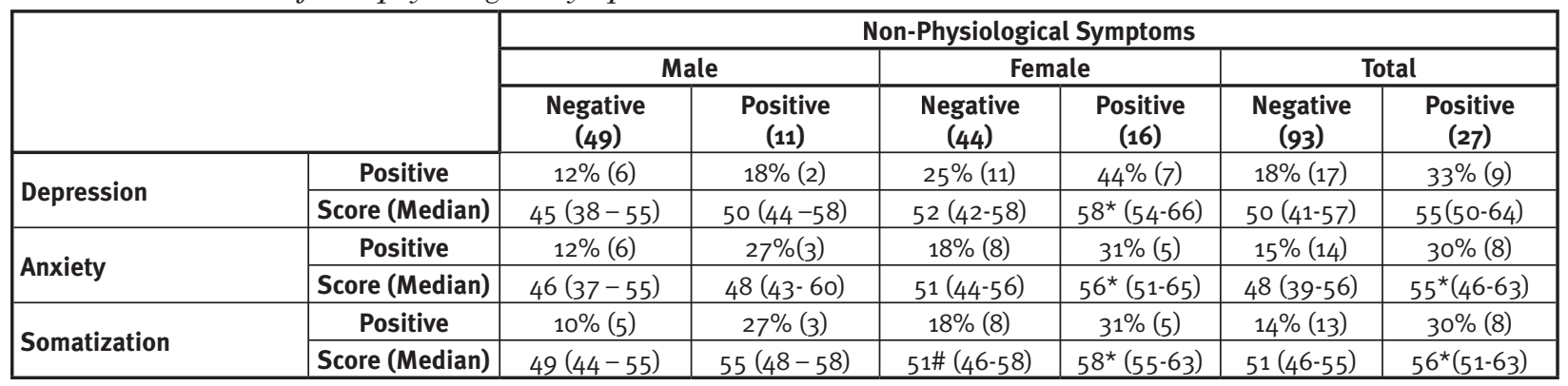

* Indicates significant differences between Non-Physiological Symptoms within the same category

\# Indicates significant differences between males and females

For Continuous variables data are presented as median values (Inter-quartile ranges: $25^{\text {th }}-75^{\text {th }}$ percentile) and compared using the Mann-Whitney U test. Non-continuous variables are using the Chi-squared test. Fisher Exact test used when expected frequency values are less than 5 .

() Number of patients

Data are presented as median values (interquartile ranges: 25 th $-75^{\text {th }}$ percentile). Continuous variables are compared using the Mann-Whitney U test. Non-continuous variables are using the chi-squared test.

Table 4. Correlation of non-physiological signs

\begin{tabular}{|c|c|c|c|c|c|c|c|}
\hline & & \multicolumn{6}{|c|}{ Non-Physiological Signs } \\
\hline & & \multicolumn{2}{|c|}{ Male } & \multicolumn{2}{|c|}{ Female } & \multicolumn{2}{|c|}{ Total } \\
\hline & & Negative (50) & $\begin{array}{c}\text { Positive } \\
\text { (10) }\end{array}$ & $\begin{array}{l}\text { Negative } \\
\text { (36) }\end{array}$ & $\begin{array}{c}\text { Positive } \\
\text { (24) }\end{array}$ & $\begin{array}{c}\text { Negative } \\
\text { (86) }\end{array}$ & $\begin{array}{c}\text { Positive } \\
\text { (34) }\end{array}$ \\
\hline \multirow[b]{2}{*}{ Depression } & Positive & $10 \%(5)$ & $30 \%(3)$ & $22 \%(8)$ & $42 \%(10)$ & $15 \%(13)$ & $38 \% *(13)$ \\
\hline & $\begin{array}{c}\text { Score } \\
\text { (Median) }\end{array}$ & $45(38-52)$ & $53(47-59)$ & $50(42-58)$ & $58(54-64)$ & $47(41-55)$ & $56^{*}(51-62)$ \\
\hline \multirow[b]{2}{*}{ Anxiety } & Positive & $10 \%(5)$ & $40 \% *(4)$ & $19 \%(7)$ & $25 \%(6)$ & $14 \%(12)$ & $29 \% *(10)$ \\
\hline & $\begin{array}{c}\text { Score } \\
\text { (Median) }\end{array}$ & $44(36-52)$ & $56^{*}(53-60)$ & $51(41-56)$ & $55(46-61)$ & $47(38-55)$ & $55^{*}(48-60)$ \\
\hline \multirow[b]{2}{*}{ Somatization } & Positive & $8 \%(4)$ & $40 \% *(4)$ & $22 \%(8)$ & $21 \%(5)$ & $14 \%(12)$ & $27 \%(9)$ \\
\hline & $\begin{array}{c}\text { Score } \\
\text { (Median) }\end{array}$ & $49(43-55)$ & $57^{\star}(48-59)$ & $51 \#(46-60)$ & $55(51-61)$ & $51(45-55)$ & $56^{*}(50-59)$ \\
\hline
\end{tabular}

* Indicates significant differences between Non-Physiological Symptoms within the same category \# Indicates significant differences between males and females

For Continuous variables data are presented as median values (Inter-quartile ranges: 25 th - 75th percentile) and compared using the Mann-Whitney $U$ test. Non-continuous variables are using the Chi-squared test. Fisher Exact test used when expected frequency values are less than 5 .

() Number of patients

Data are presented as median values (interquartile ranges: 25 th -75 th percentile). Continuous variables are compared using the Mann-Whitney $U$ test. Non-continuous variables are using the chi-squared test.

Among the men, significant correlation was observed with elevated anxiety scores and the elevated scores and diagnosis of somatization. In contrast, among women, significant correlation was observed only with elevated scores of depression and somatization, but not with diagnosis.

There were no significant differences noted between positive men and women. These differences are illustrated in Table 5.

\section{Correlation Among Multiple Variables}

As shown in Table 6, multiple variables including gender, duration of pain, average pain rating, non-physiological signs, depression scores and diagno- sis of depression, anxiety and somatiza- tients with non-physiological symptoms. tion showed significant correlation noted In contrast, there was no such correlaamong multiple variables.

\section{DisCUSSION}

Significant correlations were observed with non-physiological signs in men with elevated scores and diagnosis of anxiety and somatization. In contrast, there were no correlations either with the elevated scores or the diagnosis of any psychological variables with nonphysiological signs among women. However, among women, there was significant correlation with elevated scores of depression, anxiety and somatization in pa- tion observed for men in these categories. Correlations were similar for patients presenting with combined non-physiological symptoms and signs with psychological variables. Positive correlation was seen with elevated scores and positive diagnosis in all three categories. However, among men, positive correlation was seen only with elevated anxiety scores and with elevated scores and diagnosis of somatization. Among women, the correlation was seen with elevated scores of depression and somatization. There were no differences noted among the positive group of 
Table 5. Combined non-physiological symptoms and signs

\begin{tabular}{|c|c|c|c|c|c|c|c|}
\hline & & \multicolumn{6}{|c|}{ Combined Non-Physiological Symptoms and Signs } \\
\hline & & \multicolumn{2}{|c|}{ Male } & \multicolumn{2}{|c|}{ Female } & \multicolumn{2}{|c|}{ Total } \\
\hline & & $\begin{array}{c}\text { Negative } \\
\text { (53) }\end{array}$ & $\begin{array}{c}\text { Positive } \\
(7)\end{array}$ & $\begin{array}{l}\text { Negative } \\
\text { (48) }\end{array}$ & $\begin{array}{c}\text { Positive } \\
\text { (12) }\end{array}$ & $\begin{array}{l}\text { Negative } \\
\text { (101) }\end{array}$ & $\begin{array}{c}\text { Positive } \\
\text { (19) }\end{array}$ \\
\hline \multirow[b]{2}{*}{ Depression } & Positive & $11 \%(6)$ & $29 \%(2)$ & $25 \%(12)$ & $50 \%(6)$ & $18 \%(18)$ & $42 \% *(8)$ \\
\hline & $\begin{array}{c}\text { Score } \\
\text { (Median) }\end{array}$ & $45(39-53)$ & $55(45-60)$ & $52(44-60)$ & $58 *(55-64)$ & $50(41-57)$ & $58^{*}(54-64)$ \\
\hline \multirow[b]{2}{*}{ Anxiety } & Positive & $11 \%(6)$ & $43 \%(3)$ & $19 \%(9)$ & $33 \%(4)$ & $15 \%(15)$ & $37 \% *(7)$ \\
\hline & $\begin{array}{c}\text { Score } \\
\text { (Median) }\end{array}$ & $46(37-55)$ & $56^{*}(48-61)$ & $51(44-59)$ & $56(51-65)$ & $48(39-56)$ & $56^{*}(51-63)$ \\
\hline \multirow[b]{2}{*}{ Somatization } & Positive & $9 \%(5)$ & $43 \% *(3)$ & $19 \%(9)$ & $33 \%(4)$ & $14 \%(14)$ & $37 \% *(7)$ \\
\hline & $\begin{array}{c}\text { Score } \\
\text { (Median) }\end{array}$ & $49(44-55)$ & $56^{\star}(49-63)$ & $51 \#(48-58)$ & $59^{\star}(55-63)$ & $51(46-55)$ & $56^{*}(55-63)$ \\
\hline
\end{tabular}

* Indicates significant differences between Non-Physiological Symptoms within the gender

\# Indicates significant differences between gender within the Non-Physiological Symptoms the gender

For Continuous variables data were presented as median values (Inter-quartile ranges: 25 th - 75 th percentile) and compared using the Mann-Whitney $U$ test. Non-continuous variables are using the Chi-squared test. Fisher Exact test used when expected frequency values are less than 5 .

() Number of patients

Data were presented as median values (interquartile ranges: 25 th $-75^{\text {th }}$ percentile). Continuous variables are compared using the Mann-Whitney $U$ test. Non-continuous variables are using the chi-squared test.

patients in both sexes.

Overall, the study demonstrated that there is a significant presence of psychological symptomatology with behavioral symptoms; men correlating well with psychological variables with non-physiological signs and women correlating well with non-physiological symptoms with psychological variables. While the overall correlation was significant with all three psychological variables with non-physiological signs and also the combination of non-physiological symptoms and signs, correlation was only present moderately with non-physiological symptoms for the overall population of the study. There was significant correlation with non-physiological symptoms for the female population in contrast to significant correlation with psychological variables of anxiety and somatization for non-physiological signs in the male population. Overall, anxiety presented with the highest correlations, followed by somatization, followed by depression.

The results of this study showed that overall, 27 patients (22\%) presented with non-physiological symptoms, 34 patients $(28 \%)$ with non-physiological signs and 19 patients (16\%) with a combined presence of non-physiological signs and symptoms. There was overall significant correlation with non-physiological signs with depression, anxiety, and somatization, both by diagnosis of depression, diagnosis of anxiety and elevated scores.
However, the overall correlation was present for non-physiological symptoms only with elevated scores of anxiety and somatization. In contrast, there were significant correlations for women with scores of depression, anxiety and somatization .

Dickens et al (17) showed that patients with and without excessive pain behavior had similar levels of anxiety and depression. They also showed that when men were studied separately, those with excessive pain behavior were more anxious and depressed than those without excessive pain behavior. No such difference was seen when women were studied alone (17). Further, they also showed that anxiety and depression scores were not correlated with the number of non-organic symptoms or signs. In contrast to the results of Dickens et al (17), our study showed significantly higher levels of depression scores, diagnosis of depression and somatization, prevalence of nonphysiological signs and anti-depressant therapy in females.

Pain behaviors were initially described by Fordyce (20). These pain behaviors may appear inappropriate at times with significant disparity between subjective complaints and so-called objective findings (26). Waddell et al (26) showed that excessive pain behaviors are common in patients with chronic low back pain with reports showing as many as $50 \%$ of the patients following work injury, 33\% of the patients in tertiary referral cen- ters, and $12 \%$ of the patients with previously untreated back pain. In the past, it has been shown that in an interventional pain management setting, $29 \%$ of the patients presented with non-physiological symptoms and 23\% with non-physiological signs (21). The extensive experience of Waddell et al led to the development of non-physiological signs and symptoms. While it was their hope that such an evaluation of the patient could lead to better utilization of inappropriate surgical and diagnostic procedures, they also cautioned that elderly patients manifested some or all of these signs without any correlation to illness behavior and often had pathology that seemed to explain their symptoms (26). Further, they clearly described that the presence of these signs was independent of the presence of structural pathology and these behavioral signs never contradicted the existence of structural pathology. The entire usefulness of these signs was that something in addition to the changes in a person's spine was responsible for their symptoms generation and claim of disability. In 1986, Waddell et al (28) published another study showing that physical factors, such as medical diagnosis, imaging studies and surgical findings were the predominant determinants of physical outcome but that psychological factors affected persistence of disability and abnormal illness behavior after surgery. Since the original description by Waddell et al (26), a multitude of 
Table 6. Correlation among demographic, behavioral and psychological factors

\begin{tabular}{|c|c|c|c|c|c|c|c|c|c|c|}
\hline & Gender & $\begin{array}{c}\text { Pain } \\
\text { Duration }\end{array}$ & $\begin{array}{l}\text { Average } \\
\text { Pain } \\
\text { Rating } \\
\end{array}$ & $\begin{array}{c}\text { Non- } \\
\text { Physiological } \\
\text { Symptoms } \\
\end{array}$ & \begin{tabular}{|c} 
Non- \\
$\begin{array}{c}\text { Physiological } \\
\text { Signs }\end{array}$ \\
\end{tabular} & \begin{tabular}{|c} 
Depression \\
Score
\end{tabular} & $\begin{array}{c}\text { Diagnosis of } \\
\text { Depression }\end{array}$ & $\begin{array}{l}\text { Anxiety } \\
\text { Score }\end{array}$ & $\begin{array}{c}\text { Diagnosis } \\
\text { of } \\
\text { Anxiety }\end{array}$ & $\begin{array}{c}\text { Somatization } \\
\text { Score }\end{array}$ \\
\hline $\begin{array}{l}\text { Pain } \\
\text { Duration }\end{array}$ & 0.071 & & & & & & & & & \\
\hline $\begin{array}{l}\text { Average } \\
\text { Pain Rating }\end{array}$ & $0.182^{\star}$ & -0.044 & & & & & & & & \\
\hline $\begin{array}{l}\text { Non- } \\
\text { Physiological } \\
\text { Symptoms }\end{array}$ & 0.100 & -0.062 & $0.180^{\star}$ & & & & & & & \\
\hline $\begin{array}{l}\text { Non- } \\
\text { Physiological } \\
\text { Signs }\end{array}$ & $0.259^{\star \star}$ & -0.038 & 0.144 & $0.503^{\star *}$ & & & & & & \\
\hline $\begin{array}{l}\text { Depression } \\
\text { Score }\end{array}$ & $0.289^{\star}$ & 0.042 & 0.090 & $0.302^{\star \star}$ & $0.380^{* *}$ & & & & & \\
\hline $\begin{array}{l}\text { Diagnosis of } \\
\text { Depression }\end{array}$ & $0.202^{*}$ & 0.034 & -0.001 & 0.153 & $0.253^{\star \star}$ & $0.547^{\star \star}$ & & & & \\
\hline \begin{tabular}{|l|} 
Anxiety \\
Score
\end{tabular} & $0.192^{*}$ & -0.050 & 0.073 & $0.249^{\star \star}$ & $0.319^{\star \star}$ & $0.822^{\star *}$ & $0.445^{* *}$ & & & \\
\hline $\begin{array}{l}\text { Diagnosis of } \\
\text { Anxiety }\end{array}$ & 0.086 & -0.005 & -0.037 & 0.157 & $0.180^{*}$ & $0.412^{\star \star}$ & $0.640^{\star \star}$ & $0.555^{* \star}$ & & \\
\hline $\begin{array}{l}\text { Somatization } \\
\text { Score }\end{array}$ & $0.273^{*}$ & 0.171 & $0.303^{\star \star}$ & $0.322^{\star \star}$ & $0.295^{\star \star}$ & $0.659^{\star \star}$ & $0.361^{\star \star}$ & $0.614^{\star \star}$ & $0.297^{\star \star}$ & \\
\hline $\begin{array}{l}\text { Diagnosis of } \\
\text { Somatization }\end{array}$ & 0.110 & 0.115 & $0.185^{\star}$ & 0.172 & 0.148 & $0.379^{\star \star}$ & $0.610^{\star *}$ & $0.346^{\star \star}$ & $0.519^{\star \star}$ & $0.504^{\star \star}$ \\
\hline
\end{tabular}

* Correlation is significant at the 0.05 level (2-tailed).

** Correlation is significant at the 0.01 level (2-tailed).

other authors have published articles that have used and misused these signs. Consequently, the literature has become a battleground for those who wish to defend or attack the utility of Waddell's signs, and other methods of patient assessment based on their convenience. Main and Waddell (29) clarified that "non-organic signs" are a warning to the healthcare provider that a more complete psychological assessment is warranted to understand the genesis of the patient's symptoms and disability and events in the spine are not adequate to explain the patient's symptomatology and will not predict return to work or continued illness behavior after surgery. Waddell et al (29) warned that these signs must not be interpreted simplistically as faking and it is essential to assess the whole clinical picture before drawing conclusions. They clarified that the non-organic or behavioral signs are clearly separable from the standard signs of physical disease and are closely related to emotional distress. Thus, they form part of the complex of emotional and behavioral patterns. They should be regarded as the clinical presentation of psychological distress as a form of patient-doctor communication or the patient's cry for help (30). Non-organic symptoms described by Waddell et al (27) have not been extensively studied. Further, they have not been standardized.

In this study, we have used the Pain Patient Profile or P-3, which is designed specifically for chronic pain patients. Thus, we have avoided the use of self-rated scales, validated for use in subjects with psychiatric illness which may in fact provide spuriously exaggerated scores when used in subjects with low back pain. Consequently, the exaggerated scores may result in an increased magnitude of the association, making the results not only difficult to interpret, but also invalid $(31,32)$. Further, multiple authors, including Waddell et al, have published not only on the importance of psychological evaluation, but also performing them accurately and applying the results to chronic pain patients in the context of non-physiological behavior (33-36).

The prevalence of depression (22\%), anxiety $(18 \%)$, and somatization $(17 \%)$ in this study, while similar to some previous studies, is less than in some other studies. However, we have also looked at the proportion of patients on anti-depressant therapy and anti-anxiety thera- py. This revealed that a significantly higher proportion of patients were on anti-depressant therapy and anti-anxiety therapy, compared to the prevalence of depression and anxiety indicating depression and anxiety may have been controlled to a significant extent in the patients who are on this therapy (37-42). Using the nonphysiological signs criteria described by Waddell et al (26), we found the overall prevalence of $28 \%$ with $17 \%$ in men and $40 \%$ in women. This is similar to previous evaluations $(17,26)$. Dickens et al (17) found the number of patients with excessive pain behavior overall as $31 \%$ with $19 \%$ of males and $43 \%$ of females. Based on the criteria developed by Waddell et al (27) non-physiological symptoms were seen in overall $23 \%$ of the patients with $18 \%$ among males and $27 \%$ among women. This shows a significant distinction with a higher prevalence of non-physiological signs, symptoms and combination thereof among women.

The findings of this study show a significant association of depression, anxiety, and somatization with non-physiological signs and combination of signs and symptoms. This is contrast to the previous findings of Dickens et al (17). 
However, we found significant differences in the association of depression, anxiety and somatization with non-physiological signs, symptoms and combination thereof when the analysis was performed for men and women separately. In contrast to the previus studies, depression was a weak correlator in both sexes and men showed a trend towards the psychological distress with non-physiological pain behaviors. Women presented with a significantly greater proportion not only with non-physiological symptoms, but also with depression, anti-depressant therapy and anti-anxiety therapy even though the correlation among the variables was poor. Thus, our results agree somewhat with those of Dickens et al (17). These results also reinforce significant gender differences as demonstrated by Dickens et al (17) but not found in other studies (26, 35). Even though we have selected an equal number of patients from both sexes and the numbers have been reasonable with sixty in each group, there may still be gender bias or bias in the overall results based on sample size.

In summary, the clinical implications of non-physiological behavior may indicate underlying depression, anxiety and somatization. However, underlying psychological issues are present in only approximately $27 \%$ to $42 \%$ of the patients with non-physiological behavior.

\section{Conclusion}

This evaluation demonstrated the presence of non-physiological signs and symptoms in $40 \%$ and $27 \%$ of females, $17 \%$ and $18 \%$ of the males, and $28 \%$ and $22 \%$ of overall sample respectively. There was significant correlation with positive psychological diagnosis and elevated scores of depression, anxiety and somatization within the overall sample. However, correlations were not uniform and significant across the psychological conditions for men and women.

\section{ACKNOWLEDGMENTS}

We would like to thank Kim Damron, RN, Carla Beyer, RN, BSN, Renee Barnhill, RN, BSN clinical coordinators; Marla K. Neihoff and Lorie A. Caldwell medical records coordinators; and Tonie Hatton, transcriptionist, for their assistance in and preparation of this manuscript.

\section{Author Affiliation: \\ Laxmaiah Manchikanti, MD \\ Medical Director \\ Pain Management Center of \\ Paducah \\ 2831 Lone Oak Road, \\ Paducah, Kentucky 42003 \\ E-mail drm@apex.net \\ Bert Fellows, MA \\ Clinical Psychologist \\ Pain Management Center of \\ Paducah \\ 2831 Lone Oak Road \\ Paducah, Kentucky 42003 \\ E-mail at bert@thepainmd.com.}

\section{Vijay Singh, MD}

Medical Director

Pain Diagnostic Associates

1601 Roosevelt Road

Niagara, Wisconsin 54151

E-mail vsingh@netnet.net

\section{Vidyasagar Pampati, MSc}

Statistician

Pain Management Center of

Paducah

2831 Lone Oak Road

Paducah, Kentucky 42003

E-mail sagar@thepainmd.com.

\section{RefEREnCES}

1. Hellsing A, Bryngelsson I. Predictors of musculoskeletal pain in men. A twentyyear follow-up from examination at enlistment. Spine 2000; 25:3080-3086.

2. Lawrence RC, Helmick CG, Arnett FC. Estimates of the prevalence of arthritis and selected musculoskeletal disorders in the United States. Arthritis Rheum 1998; 41: 778-799.

3. Manchikanti L, Singh V, Saini B. Epidemiology of low back pain. In Manchikanti L, Slipman CW, Fellows B (eds), Interventional Pain Management: Low Back Pain - Diagnosis and Treatment. ASIPP Publishing, Paducah, KY 2002; 3-20.

4. Cassidy D, Carroll L, Cotê P: The Saskatchewan Health and Back Pain Survey. The prevalence of low back pain and related disability in Saskatchewan Adults. Spine 1998; 23:1860-1867.

5. Gagliese L, Katz J. Medically unexplained pain is not caused by psychopathology. Pain Res Manage 2000; 5:251-257.

6. Bogduk N. Musculoskeletal pain: Toward precision diagnosis. Progress in pain research and management. In Jensen TS, Turner JA, Wiesenfeld-Hallin Z (eds). Proceedings of the 8th World Congress on Pain. IASP Press, Seattle, 1997, pp 507-
525.

7. Manchikanti L, Singh V, Kloth D et al. Interventional techniques in the management of chronic pain: Part 2.0. Pain Physician 2001; 4:24-96.

8. Manchikanti L, Staats P, Singh V et al. Evidence-based practice guidelines for interventional techniques in the management of chronic spinal pain. Pain Physician 2003; 6:3-87.

9. Hendler NH, Bergson C, Morrison C. Overlooked physical diagnoses in chronic pain patients involved in litigation. Part 2. Psychosomatics 1996; 37:509-517.

10. Hendler NH, Kolodny AL. Using medication wisely in chronic pain. Patient Care 1992; May 15:125.

11. Staats PS, Hekmat H, Staats AW. The psychological behaviorism theory of pain: A basis for unity. Pain Forum 1996; 5:194-207.

12. Manchikanti L, Fellows B, Singh V. Understanding psychological aspects of chronic pain in interventional pain management. Pain Physician 2002; 5:57-82.

13. von Knorring L. Idiopathic pain and depression. Qual Life Res 1994; 3:S57-S68.

14. Lipowski ZJ. Somatization and depression. Psychosomatics 1990; 31:13-21.

15. Maier W, Falkai P. The epidemiology of comorbidity between depression, anxiety disorders and somatic disease. Int Clin Psychopharmacol 1999; 14:S1-S6.

16. Jorgensen CK, Fink F, Olesen F. Psychological distress among patients with musculoskeletal illness in general practice. Psychosomatics 2000; 41:321-329.

17. Dickens C, Jayson M, Creed F. Psychological correlates of pain behavior in patients with chronic low back pain. Psychosomatics 2002; 43:42-48.

18. Gamsa A. The role of psychological factors in chronic pain. I. A half century of study. Pain 1994; 57:5-15.

19. Covington EC. Psychogenic pain -What it means, why it does not exist, and how to diagnose it. Pain Med 2000; 1:287-294.

20. Fordyce WE. Behavioral methods for chronic pain assessment. CV Mosby Co, St. Louis, 1976.

21. Manchikanti L, Pampati VSS, Fellows B, Beyer C, Damron K, Barnhill R, Burks T. Characteristics of chronic low back pain in patients in an interventional pain management setting: A prospective evaluation. Pain Physician 2001; 4:131-142.

22. Manchikanti L, Fellows B, Pampati VS et al. Comparison of psychological status of chronic pain patients with general population. Pain Physician 2002; 5:40-48.

23. Manchikanti L, Pampati VS. Research designs in interventional pain management: Is randomization superior, desirable or essential? Pain Physician 2002; 5:275-284.

24. Manchikanti L, Pampati VS, Damron K et al. Evaluation of psychological status in chronic low back pain: Comparison with general population. Pain Physician 2002; 5:149-155. 
25. Manchikanti L, Pampati VS, Beyer C, Damron K. Do number of pain conditions influence emotional status? Pain Physician 2002; 5:200-205.

26. Waddell G, McCulloch JA, Kummel E et al. Nonorganic physical signs in low back pain. Spine 1980; 5:117-125.

27. Waddell G, Main CJ, Morris EW et al. Chronic low back pain, psychologic distress, and illness behavior. Spine 1984; 9: 209-213.

28. Waddell G, Morris EW, Di Paola et al. A concept of illness tested as an improved basis for surgical decisions in low back disorders. Spine 1986; 11:712-719.

29. Main CJ, Waddell G. Behavioral responses to examination. A reappraisal of the interpretation of "non-organic signs." Spine 1998; 23:2367-2371.

30. Waddell G, Turk DC. Assessment of low back pain. In Turk DC, Melzack R (eds). Handbook of Pain Assessment, 2nd Ed. Guilford Press, New York, 2001.

31. Pincus T, Callahan LF, Bradley LA et al. El- evated MMPI scores for hypochondriasis, depression, and hysteria in patients with rheumatoid arthritis reflect disease rather than psychological status. Arthritis Rheum 1986; 29:1456-1465.

32. Pincus T, Williams A. Models and measurement of depression in chronic pain. J Psychosom Res 1999; 47:211-219.

33. Waddell G, Newton M, Henderson I et al. A Fear-Avoidance Beliefs Questionnaire (FABQ) and the role of fear-avoidance beliefs in chronic low back pain and disability. Pain 1993; 52:157-168.

34. Waddell G, Pilowsky I, Bond MR. Clinical assessment and interpretation of abnormal illness behavior in low back pain. Pain 1989; 39:41-53.

35. Novy DM, Collins HS, Nelson DV et al. Waddell signs: Distributional properties and correlates. Arch Phys Med Rehabil 1998; 79:820-822.

36. Main CJ, Wood PL, Hollis S et al. The distress and risk assessment method. A simple patient classification to identify dis- tress and evaluate the risk of poor out come. Spine 1992; 17:42-52.

37. Kinney R, Gatchel R, Polantin P et al. Prevalence of psychopathology in acute and chronic low back pain patients. J Occup Rehabil 1993; 3:95-103.

38. Kramlinger KG, Swanson DW, Maruta T. Are patients with chronic pain depressed? Am J Psychiatry 1983; 140:747-749.

39. Magni G. Chronic low back pain and depression: An epidemiological survey. Acta Psychiatr Scand 1984; 70:614-617.

40. Fishbain DA, Cutler R, Rosomoff $\mathrm{HL}$ et al. Chronic pain associated depression: Antecedent or consequence of chronic pain? A review. Clin J Pain 1997; 13:116-137.

41. Fishbain DA. Somatization, secondary gain, and chronic pain: Is there a relationship? Curr Rev Pain 1998; 6:101-108.

42. Fishbain DA, Goldberg M, Meagher BR et al. Male and female chronic pain patients categorized by DSM-III psychiatric diagnostic criteria. Pain 1986; 26:181-197. 